\title{
Public education and the electro- optical industry: a strategic partnership in creating photonics classes for high school students
}

Neal Miller, Pearl John

Neal Miller, Pearl V. John, "Public education and the electro-optical industry: a strategic partnership in creating photonics classes for high school students," Proc. SPIE 3831, Sixth International Conference on Education and Training in Optics and Photonics, (16 June 2000); doi: 10.1117/12.388740

Event: Education and Training in Optics and Photonics (ETOP'99), 1999, Cancun, Mexico 


\title{
Public Education and the Electro-Optical Industry: A Strategic Partnership in Creating Photonics Classes for High School Students \\ Neal Miller, Optics \& Photonics Training Systems, Columbia, MO \\ Pearl John, Instructor, Columbia Area Career Center, Columbia, MO
}

\begin{abstract}
The demand for precision and efficiency is changing the way manufacturers from an array of industries are utilizing photonic and electro-optical technologies. This new demand has created a need for more specially trained operators than our post-secondary programs can supply. An over looked resource for solving industries personnel problems is the local tech prep high school. These programs already have 1) life long learning, 2) making technology accessible, and 3) transition from school to work as goals. They have $75 \%$ of the needed equipment in their electronic, computer, and technology labs. Add the missing laser labs and you can start a Laser Electro-Optical Technician training program at the secondary level.
\end{abstract}

Keywords: high school, LEOT, laser, photonics, optics, CORD, Columbia Area Career Center.

\section{BACKGROUND}

As demands for efficiency and precision escalate, manufacturers from an array of industries are turning to photonic and electro-optical technologies for solutions. This trend has been well-documented over the course of the past few years. The National Research Council, in its most recent report "Harnessing Light: Optical Science and Engineering for the 21st Century," predicts that "harnessing the properties of light will lead to a technology revolution having a pervasive impact on life in the next century." The fields of high speed data, audio, and video telecommunications offer excellent examples.

The bulk of America's technical/scientific education has been delivered by a combination of three institutions: the military, colleges and universities, and to some extent, vocational technical schools. To the extent that specific training is not available in any particular field, private industry has closed the gap by providing in-house, privately funded job training. Unfortunately, this traditional mix of educational opportunities will not be sufficient to fill the demand for hundreds of thousand of trained LEOTs within the next five years.

The military no longer provides the United States with a steady supply of equipment technicians, particularly with regard to photonics experts. Fewer funds have been expended to broaden training courses to include new technologies such as photonics.

The lack of LEOT programs at colleges, universities and technical schools adds to the problem. Fewer than 200 post-secondary educational institutions in the United States have any kind of photonics courses as part of their curricula, with fewer than 20 offering two-year LEOT programs. This means that it would take these institutions nearly 200 years to fill the industry needs created by the year 2003. Presently, postsecondary institutions can provide less than one percent of the actual demand for LEOTs each year as predicted by the National Research Council. All of these programs require two to four years of classroom instruction. This lag time in training far outstrips the realistic demands of the manufacturing sector. Bottom line, manufacturers will not spend billions of dollars building new facilities and wait two to four years for their operators.

This leaves the manufacturers as the only remaining entity that could effectively train and fill the demand for LEOTs in any realistic time frame. Major corporations will be forced to shoulder the primary responsibility for training a new generation of technical experts, and will probably do so at great expense and with an inordinate level of program duplication unless an alternative could be devised. 


\section{PUBLIC EDUCATION AND ELECTRO-OPTICS}

Currently, an alternative to this skilled training scenario exists. The program could show significant savings in training costs to manufacturing companies, incorporate cost sharing structures into secondary education programs, introduce basic concepts of photonics and lasers to an increasingly younger audience, and help restart the process of private industry reinvesting in public education.

The program shifts the focus of training from the traditional post-secondary programs to the more easily accessible and certainly more numerous high school laboratories, or to the Tech Prep schools which have already realized the value of partnering with private businesses. This model takes advantage of the significant investment that has already been made at the secondary level in facilities such as computer, electronics, and physics labs. These facilities can serve as the foundation for LEOT instruction. With additional laser labs, $100 \%$ of basic LEOT training could occur on the campuses of nearly every high school in this country.

The benefits of creating a public/private partnership between secondary schools and manufacturers are abundantly clear. First, the investment in scientific facilities and materials benefits both the manufacturer and the public school student. Manufacturers obtain a local, well-equipped training site, and public school systems realize enhanced educational facilities using the latest technology which can be employed in a regular high school curriculum without significant budget outlays. Second, when high school students see adults taking the same physics classes they do, it speaks volumes about the importance of these classes and workforce based educational curriculum.

This introduction of a new technology into the public school curriculum will heighten awareness of photonics as a career avenue in much the same way as the introduction of computer curricula affected the educational psyche of high school students during the 1980s. Also, any students utilizing the new facilities resulting from this public/private partnership will find themselves ahead of the learning curve should they decide to continue with a career in photonics.

It is estimated that an additional 500 to 5,000 high school based programs could be established to provide LEOT training during the next five years. The implementation is limited only by geographical distribution of private companies that employ LEOTs in their manufacturing processes along with their willingness to enter into such agreements.

\section{PRIVATE ELECTRO-OPTICS PROGRAM}

Between 1992 and 1997, the Columbia Area Career Center, located in Columbia, Missouri instituted a program designed to provide customized technical training through its facilities. The Career Center is an institution that offers courses in a variety of career paths to adults and students from six high schools under the auspices of the Columbia Public School District. In 1992, as an effort to expand its career path choices, the Career Center added "Principles of Technology" to its curriculum as part of the national Tech Prep movement. By upgrading its scientific and electronics labs, the Career Center was able to offer students practical applications of physical principles for possible use in a technical career.

With this upgrade in facilities, the Career Center stepped up efforts to market its facility to local manufacturers for customized training purposes. As a result of this new marketing push, in 1994 a local division of the $3 \mathrm{M}$ Corporation approached the Center with a project to train their LEOTs. A 16-week program was designed for $3 \mathrm{M}$ with the initial curriculum customized from existing LEOT materials.

$3 \mathrm{M}$ and the Career Center jointly developed a school site for this program. 3M agreed to pay for the cost of a new laser lab. and with some of the cost offset by matching state funds and training dollars, were training LEOTs at the Career Center by January, 1995. By the end of the first year sufficient interest had developed among the high school students to warrant the offering of a formal, though modified, curriculum of photonics. 


\section{THE HIGH SCHOOL PROGRAM}

Through the cooperative efforts of 3M, the Columbia Public Schools, and Neal Miller at the Career Center, a new curriculum was developed. In 1997 six classes packaged as "Introduction to Laser Technology" were offered to high school students as a practical art elective. The goal of the new course was to attract all students who had an interest in lasers in the broadest sense; eliminating the prerequisites of math or science. The course focused on practical concepts and activities, while introducing the math and science concepts within the context of the problems presented in the laser technology classes.

The course objectives were simple and straight forward. Use equipment safely, demonstrate ability to work as a team, demonstrate ability to solve problems, and demonstrate different laser applications. An emphasis is placed on research skills using the internet to support their work in the classroom. They also get to conduct their own research on a topic of their choice and present that to the class. All of this was accomplished during labs that allowed the students to make holograms, engrave key chains, find finger prints, create light shows, and create their own free space or fiber telecommunications system.

Traditional optics labs; reflection, refraction, diffraction, and polarization, with lasers as a light source, were also included.

This year (1998), Photonics I was added to the high school curriculum and Photonics II will be added in 1999. These classes have both math and science requirements such as the Principles of Technology series from CORD. This will help the students as they go forward with their careers. One unexpected benefit from these classes has been the introduction of this technology to women and minorities. Recruiters tell us that career decisions for these groups are made in high school. After that it is tool late. We have now become involved in a Saturday Science program, which requires a 50/50 female male mix.

The careful combination of both practical and academic approaches give students the ability to apply academic knowledge to real-world settings. This helps in later discussions with the basic problem solving and thinking exercises assigned. Since starting to train LEOTs for 3M using our customized 16-week fast-track program, we have added three different classes for high school students and evening classes for adults. The best recruiter for any industry is to have high school students see a real-world, real-time, workforce base curriculum in action. When that involves the same physics classes they are taking, it gets their attention.

Based on this singular experience, and taking into account the widely documented fact that LEOTs will be in high demand for both the short and long term, it would appear that specific steps can be taken now to insure that well-educated individuals will continually be available in adequate numbers to allow the implementation of new optical technologies.

To assure success we must:

1. Expand LEOT training capacities by engaging secondary and vocational/technical schools in partnerships with private corporations.

2. Use this new investment by private corporations in the public schools to introduce photonic and optical science curricula to the general secondary school population.

3. Develop and establish new LEOT training curricula which enhances overall training times for both in-house manufacturing personnel and secondary students taking these classes.

4. Promote the field of optics as a bona fide new technology within the scientific, academic, educational state and federal, and corporate communities.

5. Identify existing technologies, materials, services and suppliers of photonic and optical science services in an effort to efficiently and rapidly move into the secondary educational arena.

6. Identify or establish appropriate agencies at the state and local level to assist in expediting the establishing of photonics as a legitimate vocation. 
The adoption of these critical goals, and the subsequent implementation of the ideas represented within these goals can result in millions of students being introduced to the burgeoning field of photonics. It is important that a new generation of adults become life-long learners and can help solve the complex photonic manufacturing problems for this industry in both the short and long term future.

\section{REFERENCES}

Columbia Area Career Center, Columbia Public Schools, Columbia, MO.

CORD, Center for Occupational Research and Development, Waco, TX.

Neal Miller, "Public Education and Photonics," Optics \& Photonics News, February, pp49-50, 1999.

National Research Council, Harnessing Light: Optical Science and Engineering for the 21st Century, http://books.nap.edu/books/0309059917/html/R1.html\#R1. 